CZU 343.133

DOI: https://doi.org/10.52388/2345-1971.2021.1.14

\title{
SEPARATE ASPECTS OF THE PROSECUTOR'S PREPARATION FOR PRESENTATION OF THE STATE ACCUSATIONS IN THE COURT
}

\author{
Gheorghe SULT \\ Doctor of Law, Associate Professor, Comrat State University, \\ Comrat, Republic of Moldova \\ e-mail:sultgg@mail.ru \\ https://orcid.org/0000-0002-3636-2359
}

The article examines aspects of preparation for the presentation prosecutor's of public prosecution in criminal courts in the Republic of Moldova. The analysis of the preliminary preparation for the presentation of the public prosecution in the courts is given. Study of the materials of the criminal case, regulatory legal acts, development of a preliminary position on a criminal case, development of a plan for participation in the trial, elements of the preparation of the prosecutor for the effective support of the public prosecution. The prosecutor's analysis of the materials of the criminal case as the basis for high-quality support of the state prosecution.

Forecasting possible situations at the stage of pre-trial preparation, the use of certain tactical techniques for studying the case materials; study of normative materials and judicial practice in relation to a specific category of cases; generalization and analysis of the materials of the criminal case; forecasting various situations that may arise during the court session; a set of tactics used to solve them; build versions of the prosecution; comprehensive planning of activities to maintain public prosecution. To adequately perceive what is happening in the trial, to competently and timely respond to the behavior of the participants in the process, to investigate and collect evidence that incriminates the defendant in the commission of a crime.

Keywords: criminal case, judicial policy,public accusations, judicial process, prosecutor.

\section{UNELE ASPECTE ALE PREGĂTIRII PROCURORULUI PENTRU PREZENTAREA ACUZAȚIILOR PUBLICE ÎN INSTANȚA DE JUDECATĂ}

Articolul examinează unele aspecte ale pregătirii procurorului pentru prezentarea acuzațiilor în instanțele de judecată din Republica Moldova. Este prezentată analiza pregătirii preliminare pentru prezentarea acuzațiilor, procesul de studiere a materialelor dosarului penal, a actelor juridice de reglementare, elaborarea unei poziții preliminare cu privire la dosarul penal, elaborarea unui plan de participare la proces, elemente de pregătire procurorului pentru susținerea acuzațiilor. Un loc aparte îl ocupă analiza de către procuror a materialelor dosarului penal drept bază pentru susținerea în instanță a acuzațiilor de stat.

Autorul acordă o deosebită atenție prognozării unoreventuale situații care pot apărea la etapa de pregătire către proces, utilizării anumitor tehnicitactice pentru studierea materialelor dosarului; studierii materialelor, actelor normative și a practicii judiciare în raport cu o anumită categorie de dosare; generalizării și analizei materialelor dosarului penal; prognozării diferitelor situații care pot apărea în timpul ședinței judecătorești; elaborării unui set de tactici folosite pentru soluționarea acestor situații; creării de versiuni ale urmăririi penale; planificării cuprinzătoare a activităților pentru menținerea acuzațiilor ș.a.

Cuvinte-cheie: dosar penal, politică judiciară, acuzații de stat, proces judiciar, procuror.

\section{CERTAINS ASPECTS DE LA PRÉPARATION DU PROCUREUR À LA PRÉSENTATION DES ACCUSATIONS PUBLIQUES DEVANT LE TRIBUNAL}

L'article examine certains aspects de la préparation du procureur à la présentation des accusations devant les tribunaux de la République de Moldova. L'analyse de la préparation préliminaire à la 
présentation des accusations, le processusd'étude des matériaux de l'affairepénale, les actes juridiques réglementaires, l'élaborationd'une position préliminaire sur l'affairepénale, l'élaboration d'un plan de participation au procès, des éléments de préparation du procureur pour la poursuite des accusations estprésentée. Une place particulière estoccupée par l'analyse du procureur des matériaux de l'affaire pénale comme base pour soutenirdevant le tribunal les accusations d'état. L'auteur accordeune attention particulière à la prévision des situations possibles qui peuventsurvenir au stade de la préparation du processus, l'utilisation de certaines techniques tactiques pour l'étude des matériaux de l'affaire pénale; l'étude des matériaux, des actes normatifs et de la pratique judiciaire en relation avec une certaine catégorie de dossiers; généralisation et analyse des matériaux de l'affaire pénale; prévision des differents situations pouvant survenirlors de l'audience devant le tribunal; l'élaboration d'un ensemble de tactique sutilisées pour résoudreces situations; création de versions de poursuites pénales; planification complète des activités pour maintenir les accusations, etc.

Mots-clés: affaire pénale, politique judiciaire, accusations publiques, processus judiciaire, procureur.

\section{ОТДЕЛЬНЫЕ АСПЕКТЫ ПОДГОТОВКИ ПРОКУРОРА К ПРЕДСТАВЛЕНИЮ ГОСУДАРСТВЕННОГО ОБВИНЕНИЯ В СУДЕБНОЙ ИНСТАНЦИИ}

В статье рассматриваются аспекты подготовки к представлению прокурором государственного обвинения по уголовным делам в судебных инстанциях Республики Молдова. Приводится анализ предварительной подготовки к представлению государственного обвинения в судах. Отдельное внимание уделено изучению материалов уголовного дела, нормативных и правовых актов, выработке предварительной позиции по уголовному делу, разработке плана участия в судебном разбирательстве, элементам подготовки прокурора для эффективного поддержания государственного обвинения. Также представлен анализ прокурором материалов уголовного дела как основы качественного поддержания государственного обвинения. Рассматриваются ещце такие вопросы, как прогнозирование возможных ситуаций на стадии досудебной подготовки, применение определенных тактических приемов изучения материалов дела; изучение нормативных материалов и судебной практики применительно к конкретной категории дел; обобщение и анализ материалов уголовного дела; прогнозирование различньх ситуаций, которые могут возникнуть в ходе судебного заседания; комплекс тактических приемов, используемых для их решения; построение версий обвинения; комплексное планирование деятельности по поддержанию государственного обвинения.

Ключевые слова: уголовное дело, судебная политика, государственное обвинение, судебный прочесс, прокурор.

\section{Введение}

Постановка проблемы заключается в том, что права и охраняемые законом интересы граждан и юридических лиц, на которые были осуществлены посягательства, защищаются путем рассмотрения и разрешения в судах уголовных дел с целью привлечения к уголовной ответственности лиц, совершивших преступление. В контексте современности и с учетом времени, в полной мере должны использоваться правозащитные функции всех государственных органов, в том числе и органов прокуратуры.

Практическая важность статьи заклю- чается в том, что идеи и выводы, сформулированные в ней, могут использоваться при правильном толковании прав и обязанностей института участия прокурора в уголовном процессе и анализа правового понимания судебного расследования в специализированной научной литературе и т. д.

Методология подхода. Для достижения поставленной цели и задач будет использован метод исследования предмета статьи через законодательство Республики Молдова, анализ научных мнений, публикации на вебстраницах или на бумаге в виде руководств, статей, пояснительных записок. 


\section{Основные идеи исследования}

Частью 1 ст.124 Конституции РМ [1] установлено, что прокуратура представляет общие интересы общества и защищает правопорядок, а также права и свободы граждан, руководит уголовным преследованием и осуществляет его, представляет в соответствии с законом обвинение в судебных инстанциях.

В судебном расследовании процессуальное положение каждого из субъектов содержит собственные характерные особенности. Безусловно, центральной фигурой считается суд, но и прокурор владеет широкими возможностями буквально на всех стадиях уголовного судопроизводства. В судебном расследовании главное назначение деятельности прокурора -поддержаниеё государственного обвинения.

Процессуальный статус прокурора в уголовном процессе, формы и способы его работы, задачи, решаемые в отдельной стадии, и его возможности и полномочия определены в УПК РМ.

Так, согласно ст.51 УПК РМ«Прокурор является лицом, осуществляющим в пределах своей компетенции от имени государства уголовное преследование или, в зависимости от обстоятельств, руководящим им, представляющим обвинение в суде и выполняющим другие обязанности, предусмотренные настоящим кодексом. Прокурор, участвующий в уголовном судопроизводстве, выполняет функции государственного обвинителя».Часть 3 ст.51 УПК РМ «при осуществлении своих полномочий в уголовном процессе прокурор независим и подчиняется только закону. Он должен также исполнять письменные указания вышестоящего прокурора об устранении нарушений закона и упущений, допущенных при осуществлении уголовного преследования и/или руководстве им» [3].

Исходя из обозначенных норм, указывая статус прокурора среди сторон и иных участников уголовного процесса, законодательство Республики Молдова, определяет его статус в стадии судебного разбирательства как сторону обвинения. Непосредственно данная роль прокурора зафиксирована в ч. 4 ст.51 УПК РМ «в ходе уголовного судопроизводства прокурор поддерживает обвинение от имени государства и представляет в судебном заседании доказательную базу, собранную органом уголовного преследования».

Практика демонстрирует, что правильное использование уголовного и уголовнопроцессуального законодательства при поддержании государственного обвинения, в ходе судебного расследования связана внутренней с позицией прокурора, и которое возможно отнести к эмоциональным процессам. Вследствие этого, прокурор, приходя в суд, обязан быть уверенным в обоснованности предъявленного подсудимому обвинения и в ходе судебного расследования он не только обязан вновь расценивать собранную доказательную базу, но прийти и к иным выводам по делу, чем те, которые находятся в утвержденном им обвинительном заключении. Способность пересмотреть личные выводы подразумевает присутствие у прокурора самоконтроля, стремления установить правду, в том числе и в случае, если это связано с признанием личной ошибки, это обязательное условие удачного выполнения прокурором возложенных на него обязанностей.

В психологию прокурора включается как совокупность психологических методов, которые он вправе применитьииспользоватьв своей деятельности, так и личные качества, умелый навык, опыт и юридическая квалификация. Все это невозможно отрывать от культуры судебной и уголовнопроцессуальной работы прокурора.

Собственно, необходимо обозначить, что в судебном расследовании прокурор поддерживает перед судом государственное 
обвинение, пользуясь равными правами с другими участниками судебного разбирательства (ст.5 Закона о прокуратуре РМ [2], ст.ст.53, 320 УПК РМ) [3].

Функция прокурора по поддержанию перед судом государственного обвинения выполняется в течение всего разбирательства дела, независимо от занятой позиции. В представленном направлении им принимается активное участие в исследовании доказательств, высказывает суду собственные мнения обиспользовании уголовного закона и санкционных мер в отношении подсудимого. Собственные отношения с судом прокурор строит на базе строжайшего соблюдения принципов и основ состязательности и равенства прав сторон, независимости судей и их подчинения исключительно закону.

Практика наглядно демонстрирует, что качество представления прокурором государственного обвинения в судах Республики Молдова находится в зависимости от множествамоментов. Одним из ключевых считается толковая подготовка прокурора к судебному заседанию.

Лишь только отлично подготовленный прокурор имеет возможность эффективно поддерживать обвинение и вернооткликаться на сложные ситуации, образующиеся в ходе судебного разбирательства. Неведение или слабое познание материалов уголовного дела считается предпосылкой пассивной роли прокурора по представлению государственного обвинения в судах, что в свою очередь, исключает его реальное влияние на ход и итог судебного процесса [4].

Наравне с прокурором, в кое-каком нюансе выполнение функций обвинения в той или другой степени ложится и на суд, потому что суд вынужден самостоятельно, без роли обвинителя, изучить подтверждения и исследовать доказательства, изобличающие подсудимого в совершении преступления. В случае, когда суд собственной активностью не компенсирует недостатки поддержания государственного обвинения, не исключены судебные промахи при вынесении им приговора. Исходя из обозначенного суждения, делается бесспорным высококачественной подготовки прокурора к судебному заседанию.

Стадию подготовки к судебному разбирательству проходят все дела, при этом следует принимать во внимание следующие составные элементы подготовки: использование конкретных тактических способов исследования материалов дела; исследование особой литературы, нормативных материалов и судебной практики применительно к определенной категории дел; обобщение и анализ материалов уголовного дела; прогнозирование всевозможных обстановок, способных появиться в ходе судебного заседания, и комплекс тактических способов, применяемых для их решения; построение версий обвинения; всеохватывающее планированиеработы по поддержанию государственного обвинения [5].

Особое место в представленном контексте занимает владение способов исследования материалов уголовного дела. При этом следует указать, что проблема должного исследования способов до настоящего времени практически не освещалась в юридических изданиях, поэтому практические сотрудники срабатывают в данном направлении инстинктивно и не всякий раз с необходимой эффективностью.

Абсолютно бесспорно, что для высококачественной подготовки к судебному заседанию прокурору как лицу, поддерживающего государственное обвинение нужно изучить все материалы уголовного дела, что, собственно,не всегда имеет место на практике, а используется, как правило, индивидуализм, т.е. обусловленное личностными свойствами прокурора (память, способность к анализу, логическое мышление, прогнозирование). 
Относительно способов изучения материалов уголовного дела следует выделить два наиболее свойственных: первый -исследование материалов дела наступает с постановления о возбуждении уголовного дела и длиться в том порядке, как его систематизировал офицер по уголовному преследованию или прокурор; второй - исследование начинается с обвинительного заключения, а затем исследуются другие материалы.

В ходе исследования дела принципиально вычленить из всего комплекса документов, имеющихся в нем, более значимые, на чтение и осмысление коих надо отпустить больше времени. Для приобретения этих навыков требуется не только огромный опыт поддержания государственного обвинения, но и познания в области методики расследования отдельных видов преступлений и, в соответствии с этим, особенностей поддержания государственного обвинения по разным категориям уголовных дел.

Нужно внятно представлять, что именно следует анализировать при изучении материалов уголовного дела.

К предмету такого анализа следует отнести следующее: предмет и пределы доказывания по определенному уголовному делу; подтверждения, изобличающие личность в совершении преступления; подтверждения, свидетельствующие не в пользу обвинения; данные о личности обвиняемого; нормативный материал и судебную практику по определенной категории дел.

Чрезвычайно важным в работе прокурора в стадии досудебной подготовки считается прогнозирование вероятных обстановок, которые имеют все шансыпоявиться в ходе судебного разбирательства. Оно разрешает прокурору деятельно воздействовать на ход судебного процесса, правильно понимать происходящее в нем, компетентно и вовремя откликаться на поведение других участников процесса.
К более обычным ситуациям можно отнести: изменение показаний допрашиваемым; неявка на судебное заседание конкретных лиц; выдвижение подсудимым версии собственной защиты, которая не была предметом проверки на стадии уголовного преследования; заявление ходатайств различными участниками процесса[4]. Указанный перечень ситуаций не является исчерпывающим, а считается только наиболее часто встречающимися.

Планирование работы прокурора как государственного обвинителя представляет собой комплексный, постоянный и довольно долгий процесс, который наступает с момента изучения материалов уголовного дела и заканчивается в конце судебного заседания. Потому планирование считается индивидуальным и креативным ходом, который в конкретной степени находиться в зависимости от собственных качеств прокурора, а еще от категории, объема и сложности уголовного дела. Прокурор, будучи государственным обвинителем вправе иметь несколько планов, помогающих ему решать различные задачи по поддержанию обвинения. Количество планов и их содержание зависит от объема уголовного дела, числа привлекаемых по нему лиц, вида преступления и множества иных моментов.

Среди видов планов,возможно отметить: общий план участия обвинителя в судебном рассмотрении уголовного дела; план участия прокурора в отдельном судебном действии; план поддержания обвинения по многоэпизодным делам и делам на несколько лиц; план-схема криминальных связей; план-расчет гражданских исков в уголовном процессе; план, определяющий порядок изучения и исследования доказательств [4].

Планирование поддержания государственного обвинения - это многоэтапный и комплексный процесс, итогом которого считаютсявсевозможные планы, оформлен- 
ные прокурором в зависимости от числа и характера задач, стоящих перед ним. План обязан помогать его составителю свободно ориентироваться в материалах уголовного дела, а в будущем стать почвой для подготовки выступления в прениях сторон. Этим образом, план постоянно дополняется и корректируется в ходе судебного разбирательства.

Планирование работы прокурора по поддержанию государственного обвинения обязана основываться с учетом требований ст.344 УПК РМ. А именно, ч.1 ст.344 УПК РМ «поступившее в судебную инстанцию дело в течение дня распределяется судье или, по обстоятельствам, составу суда в случайном порядке с помощью автоматизированной информационной программы управления делами» и ч. 2 ст.344 УПК РМ «выписка из автоматизированной информационной программы управления делами о случайном распределении дела и определение председательствующего судебной инстанции прилагается к делу [3].

То есть, не позже 3-дневного срока после распределения дела для судебного разбирательства судья или, в зависимости от обстоятельств состав суда, выучив материалы дела, назначает срок проведения подготовительного заседания, которое наступает не позже 20 дней со дня распределения дела, за исключением очевидных преступлений. Подготовительное заседание по делу, по которым в качестве обвиняемых проходят несовершеннолетние подсудимые или же арестованные лица, проводится в неотложном и приоритетом порядке до истечения установленного раньше срока ареста.

Также, прокурор призван брать на себя меры к устранению фактов волокиты в рассмотрении судами уголовных дел, т.е. учитывать нормы ч.1 ст.20 УПК РМ«уголовное преследование и судебное разбирательство дела осуществляются в разумные сроки» [3].
Проанализировав данные нормы, можно сделать вывод, что подготовка прокурора - это идеальное познание материалов дела. Успех судебного рассмотрения дела во многом находиться в зависимости от подготовленности прокурора к участию в процессе, от его напористости в установлении правды и профессионального умения занять позицию, основанную на законе и исходящую из материалов дела. Идеальное познание материалов уголовного дела обязательная заявка, предъявляемое к прокурору, поддерживающему государственное обвинение. Тщательное исследование прокурором материалов уголовного дела дает собою базу высококачественного поддержания государственного обвинения.

Исследование материалов уголовного дела следует организовать таким образом, чтобы прокурор изучил не только основные процессуальные документы, как это часто бывает на практике, но ознакомился со всеми без исключения материалами уголовного дела, в том числе и с теми, которые, на первый взгляд, могут показаться ему второстепенными. Располагая конспективным изложением, а то и дословными выдержками из показаний подсудимого, пострадавшего и свидетелей, прокурор имеет возможность в ходе допроса этих лиц судом и участниками судебного разбирательства сравнить их показания с теми, которые ими давались на стадии уголовного преследования или же раньше состоявшемся судебном разбирательстве. Прокурор обязан кропотливо изучить материалы уголовного дела,в том числе и в тех случаях, когда он осуществлял контроль за его преследованием или же составлял обвинительное заключение.

В случае если прокурор, идя в процесс, тщательно не исследует материалы дела, а станет рассчитывать на свою собственную находчивость, эрудицию или же практический навык, он ни разу не сможет отменно 
поддержать государственное обвинение,в том числе и по самому легкому уголовному делу. Незнание материалов дела будет всегда связывать прокурора [5].

С учетом того, что в судебном расследовании процессуальное положение прокурора в судебном расследовании - поддержание государственного обвинения, это значит, что прокурор, во всех случаях и во что бы то ни стало,обязан поддерживать обвинение. Поддерживая обвинение, прокурор руководствуется требованиями закона и собственным внутренним убеждением, базирующаяся на рассмотрении всех событий дела.

Эффективность прокурорского наблюдения при/на стадии судебного расследования в значимой мере зависит от верного определения самим прокурором собственного процессуального положения в суде. Вопрос данный содержит не только абстрактное, но и более практическое значение.

При поддержании государственного обвинения он не освобождается от обязанности осуществлять наблюдение за соблюдением законности при рассмотрении судами уголовных дел. Поддержание государственного обвинения и осуществление наблюдения за точным исполнением законов надо рассматривать как проявление личного в общем. Государственное обвинение занимает ведущее место среди других видов обвинений в судебном разбирательстве. Процессуальное положение прокурора в судебных стадиях значимовыделяется от его положения в стадии уголовного преследования. В судебном разбирательстве прокурор утрачивает «властно-распорядительные полномочия» и принимает участие в ином процессуальном качестве, а именно как государственный обвинитель - сторона в процессе [6].

Прокурор, будучи государственным обвинителем, действует от имени государства и, как ответственный перед ним, поддерживает обвинение в строгом соответствии с законом, в пределах закона и в той мере, в какой оно находит подтверждение на судебном следствии.

Одним из факторов повышения качества поддержания государственного обвинения является подготовка прокурора к судебному заседанию. Подготовка к судебному разбирательству содержит большее количество персонального, обусловленного личностнымисвойствами обвинителя, такими как память, способность к анализу, закономерному мышлению и прогнозированию. Особое место здесь занимает владение способом исследования материалов уголовного дела. Лишь только отлично информированный и подготовленный прокурор имеет возможность решить целый комплекс проблем, возникающих в ходе судебного процесса.

В деятельности прокурора важным является также досудебная подготовка. Как правило, в данной стадии исполняется прогнозирование вероятных обстановок, которые имеют все шансыпоявиться в ходе судебного разбирательства. Досудебная подготовка разрешает прокурору деятельно воздействовать на ход судебного процесса, правильно понимать происходящее в нем, компетентно и вовремяоткликаться на поведение других участников процесса.

Проанализировав кое-какие общепринятые нормы уголовно-процессуального законодательства,возможно, резюмировать, что досудебная подготовка прокурора - это идеальное познание материалов дела. Успех судебного рассмотрения дела во многом находиться в зависимости от подготовленности прокурора к участию в процессе, от его напористости в установлении правды и профессионального умения занять позицию, основанную на законе и исходящую из материалов дела.

Подготовительная часть судебного разбирательства наступает с этапа открытия судебного заседания, и длиться вплоть до начала оглашения обвинительного заключения. Роль и участие прокурора на данной 
стадии имеетбольшое значение. Необходимым фактором в подготовительной части судебного заседания заявление и разрешение ходатайств.

В подготовительной части судебного заседания прокурор дает заключение по возникающим вопросам, ответ по заявленным участниками процесса ходатайствам, сам заявляет различного рода ходатайства, высказывает собственноемнение о возможности слушания дела в отсутствие кого-либо из лиц, вызванных в судебное заседание.

Только при условии, если прокурор станеткропотливо готовиться к участию в судебном процессе, проверить полноту, всесторонность и объективность произведенного уголовного преследования, давать обоснованные на законе и материалах дела мотивированные заключения, вносить необходимые предложения по вопросам, связанным с подготовкой к рассмотрению дела в судебном заседании, содействует суду в принятии легитимного и обоснованного приговора, определения (постановления) [5].

Судебное расследование это часть судебного разбирательства, в ходе которого ведется изучение судом с участием сторон всех доказательств, важных для обоснования приговора. В данной части судебного разбирательства формируется фундамент грядущего приговора. Как правило, на судебном следствии ярко имеет место быть принцип состязательности уголовного процесса, который требует от государственного обвинителя широких знаний. В следствие этого, законность и обоснованность приговора во многом находиться в зависимости как отсвойства, качества, полноты и объективности судебного следствия, так и правильности исследования доказательств. Успех судебного следствия по делу в целом и судебного разбирательства в конкретной мере находиться в зависимости от корректности предложенного прокурором порядка изучения доказательств. Данный порядок, обязан быть таким, чтобы в строгой последовательности и наиболее эффективно были выяснены все обстоятельства уголовного дела. По завершении судебного следствия по делу и в целом судебного разбирательства, суд переходит к выслушиванию судебных прений, состоящая из речей обвинения и защиты, а так же реплик, которыми могут обменяться участники процесса по поводу сказанного в речах. Судебные прения оказывают конкретное воздействие на составление убеждения судей,содействуют больше абсолютному усвоению материалов дела, как составом судей, так и присутствующими в зале. Обвинительной речью завершается работа прокурора в судебном расследовании. При этом речь прокурора должна быть изложенаобычным и ясным языком, понятным лицам, юридически обоснованной, прокурор приводит в строгую систему доказательства, исследованные на судебном расследовании. По собственной правовой сути и процессуальному значению речь прокурора как обвинителя считается правовым актом, при помощи которого прокурор реализует собственные полномочия на суде.

Прения сторон являются той стадией судебного расследования, в которой энергичность прокурора добивается кульминации. Она считается результатом всей его работы по поддержанию государственного обвинения. Лишь только на данной стадии прокурор имеет возможность внятно и понятно изложить свою позицию по конкретному уголовному делу, которая в ходе судебного процесса могла проявляться только косвенным образом: сквозь постановку вопросов, заявление и утверждение ходатайств, дачу заключений [5].

\section{Заключение}

Констатируя результаты настоящего исследования, потенциально возможно сфор- 
мулировать мнение, что роль планирования государственным обвинителем собственной деятельности является чрезвычайно важной не только на стадии судебного следствия, но и в прениях. Тем более это проявляется при подготовке выступления по многотомным или многоэпизодным уголовным делам, когда к уголовной ответственности привлекается значительное количество лиц. Соблюдение прокурором закономерных и этических правил ведения полемики позволяет ему решить задачи, стоящие перед ним в стадии судебных прений, а также при поддержании государственного обвинения в целом.

\section{Библиография}

1. Конституция Республики Молдова от 29 июля 1994//МониторулОфичиал ал Р. Молдова № 1.

2. Закона о прокуратуре Республики Молдова от 25.02.2016//Мониторул Офичиал ал Р. Молдова №. 69-77.

3. Уголовно-процессуальный Кодекс Республики Молдова №122 от 14.03.2003// Мониторул Офичиал ал Р. Молдова №1 04-110.

4. КИСЕЕВ, Н. Уголовный процесс. Chişinău, 2006, 1176 p.

5. БОРИКО, С. Уголовный процесс. - Мн., 2000. $-398 \mathrm{c}$.

6. ИВАНОВСКИЙ, А. Новый УПК - задачи и проблемы государственного обвинения. // Юстиция Беларуси. - 2000. - №4. 